\title{
Association of household food security and dietary diversity of mother-child pairs in the Philippines
}

\author{
Mildred O. Guirindola, Ma. Lynell V. Maniego* \& Cristina G. Malabad \\ Department of Science and Technology - Food and Nutrition Research Institute, \\ Nutritional Assessment and Monitoring Division, DOST Compound, Gen. Santos Ave., \\ Bicutan, Taguig City 1631 Philippines
}

\begin{abstract}
Introduction: The majority of Filipino households experience food insecurity. Mothers and children are among the population groups suffering from poor diet quality. This study aimed to determine the extent of the association of household food security (HFS) to mothers' and children's dietary diversity score (DDS), and to identify the significant factors associated with meeting the DDS of these vulnerable groups. Methods: The study was a cross-sectional, population-based study utilising secondary data from the 2015 Updating Survey. From a total of 6,692 mother-child pairs, the association between HFS and meeting the DDS of mothers and children, as well as the potential predictors for meeting the DDS were tested using descriptive and logistic regression analyses. Results: The findings showed that HFS was significantly associated with meeting the DDS of mothers and children aged 6-36 months $(p<0.001)$. The proportion of meeting the DDS among mothers and children was significantly higher in food-secure than in food-insecure households $(20.7 \%$ vs. $14.4 \%$ ). Furthermore, meeting the DDS decreased with increasing levels of food insecurity. Household food security status, education background, employment, child's age, and wealth status were significantly associated with meeting the DDS. Conclusion: This study showed the extent of how food security was associated with meeting the DDS of mothers, children, and mother-child pairs, and the factors associated with meeting the DDS. Results can be used to strengthen the formulation of appropriate, evidence-based policies to address household food insecurity and low DDS among mothers and young children.
\end{abstract}

Keywords: household food security, dietary diversity, mother-child pairs, Philippines, NNS

\section{INTRODUCTION}

Pregnant and lactating mothers and children under five are nutritionally vulnerable because of additional energy and micronutrient requirements for their physiological needs. According to the latest estimate, maternal and child malnutrition is responsible for
$45 \%$ of mortality among children under the age of five (FAO et al., 2019). The substantial reduction of maternal and child mortality is a global priority as embodied in Sustainable Development Goal (SDG) No. 3 (Brizuela \& Tunçalp, 2017). Food-based interventions that focus on a healthy diet among children

\footnotetext{
*Corresponding author: Ms. Ma. Lynell V. Maniego

Department of Science and Technology - Food and Nutrition Research Institute,

Nutritional Assessment and Monitoring Division

DOST Compound, Gen. Santos Ave., Bicutan, Taguig City 1631 Philippines

Tel: +63 (02) 8839-1843; Fax: +63 (02) 8839-1843; E-mail: lynellmaniego@gmail.com

doi: https://doi.org/10.31246/mjn-2021-0046
} 
and women of child-bearing age is one of the established interventions to meet additional energy and micronutrient requirements for their physiological needs during the first 1000 days (Keats et al., 2021).

Despite the global and local priority accorded to maternal and child health and nutrition programmes, the results of the 2018-2019 Expanded National Nutrition Survey (ENNS) released by the Department of Science and Technology - Food and Nutrition Research Institute (DOST-FNRI) in May 2021 showed the lack of diversity in the diets of mothers and children (DOST-FNRI, 2021). Among infants aged 6-11 months, the majority of one-day food intake came from only two food groups; rice as the major source of carbohydrates at $43.6 \%$, and milk and milk products as important sources of protein at $46.6 \%$. Among children aged 1-2 years old, rice comprised $40.8 \%$ of the diet and 47.2\% among those 3-5 years old. Across these age groups of children, intakes of fruits and vegetables, eggs, dried beans accounted for $<5 \%$ of the diet, while it was also noted that children aged 1-2 years old and 3-5 years old have an intake of sugar and sugar products at $3.4 \%$ and $5.4 \%$ of the diet, respectively.

Among pregnant women and lactating mothers, more than half of one day's food intake was from rice at $51.5 \%$ and $58.3 \%$, respectively. Both pregnant women and lactating mothers consumed milk and milk products, starchy roots and tubers, fats and oils, eggs, dried beans, nuts and seeds in less significant amounts of about one to two percent of total intake per day, while sugars and syrups were at about $5 \%$ per day. Based on the same survey data, mean energy intakes versus the Philippine Dietary Reference Intakes (PDRI) were low for infants aged 6-11 months (446 kcal vs. $675 \mathrm{kcal}), 1-2$ years old (728 kcal vs. 960 kcal), and 3-5 years old (889 kcal vs.
$1305 \mathrm{kcal})$. The same result was noted among pregnant women $(1502 \mathrm{kcal}$ vs. $2200 \mathrm{kcal}$ ) and lactating mothers (1632 kcal vs. $2400 \mathrm{kcal}$ ). Based on the acceptable macronutrient distribution ranges, the majority of the diet of children six months to five years old was from carbohydrates at $63.3 \%, 13.3 \%$ from protein, and $23.4 \%$ from fats. For pregnant women, the distribution was $70.0 \%$ from carbohydrates, $13.5 \%$ from protein, and $16.6 \%$ from fats. For lactating mothers, the distribution was $72.8 \%$ from carbohydrates, $12.9 \%$ from protein, and $14.2 \%$ from fats. The higher limit for carbohydrates, but lower than recommended distribution ranges for fats and protein were noted for children and pregnant and lactating mothers.

The available data on protein adequacy showed that $70.8 \%$ of children six months to five years old were meeting protein adequacy, but only $17.2 \%$ and $19.0 \%$ among pregnant women and lactating mothers were. For Vitamin A, $68.2 \%$ of infants aged 6-11 months and about half of those aged 1-2 years old and 3-5 years old have inadequate intakes. For dietary iron, about $80 \%$ of these children have inadequate intakes. Among pregnant women and lactating mothers, $70.5 \%$ and $72.7 \%$, respectively, have inadequate Vitamin A intakes and $100 \%$ inadequacy for iron. Proportions with inadequate intakes of calcium, thiamine, and riboflavin were at about $90 \%$.

The 2019 ENNS also showed that children, pregnant women and lactating mothers were suffering from micronutrient deficiencies. Anaemia was of severe public health concern among infants aged 6-11 months at $43.1 \%$, and moderate public health significance among pregnant women at $23.0 \%$. Vitamin A deficiency (VAD) among ages $6-59$ months at $15.5 \%$ was of moderate public health significance. Iodine deficiency was also present 
among pregnant women $(21.1 \%)$ and lactating mothers $(22.0 \%)$ based on median urinary iodine concentration. The very high rates of anaemia among infants under one year possibly reflect insufficient maternal stores due to poor dietary intake during pregnancy and inadequate micronutrient contents, particularly iron and Vitamin A of complementary foods given to children in the first and second years of life (Mbuya et al, 2021).

In addition to the diversity of the diet, another key element in shaping the nutritional environment in the household is the degree to which the household experiences food insecurity. Food insecurity is related to the limited or lack of economic and physical access to adequate food (Pérez-Escamilla, 2017). The 2018-2019 ENNS results showed that using the Household Food Insecurity Access Scale (HFIAS) tool, more than half $(56.0 \%)$ of the households were food insecure, with $29.8 \%$ suffering from a moderate form of food insecurity. The December 2019 non-commissioned survey of the Social Weather Stations (SWS) also showed that 54\% of Filipino families considered themselves poor and $35 \%$ also described themselves as foodpoor during the last quarter of 2019. A self-rated poor family means that the head of the household rated the family as poor or food-poor, respectively, based on the situational questions asked (SWS, 2020).

The high prevalence of food insecurity among Filipinos can be traced to a combination of low incomes, poor choices, and high prices of nutritious foods, such as vegetables and fruits (Mbuya et al., 2021). Based on the Philippine Statistics Authority, the 2018 proportion of Filipino families living below the poverty threshold, or the proportion whose per capita income was not sufficient to meet their basic food and non-food needs was $16.6 \%$, or 17.6 million Filipinos, while poor families at $12.3 \%$ were estimated at three million (PSA, 2019). In a recent iPrice study in September 2021, findings showed that Manila has one of the most expensive cost of living and the lowest average salary compared with other Southeast Asian Countries. In addition to limited purchasing power, the price per calorie for vitamin A-rich fruits and vegetables, dark green leafy vegetables, other vegetables, other fruits, and nuts are higher in the Philippines than in lowermiddle-income countries and Southeast Asia (Mbuya et al., 2021; iPrice Group, 2021). In contrast, sugary drinks, such as soft drinks and juices, and sugary snacks are all cheaper in the Philippines than in other countries including lowand middle-income countries and Southeast Asia (Mbuya et al., 2021). Poor food choices were consistent with the study conducted by Lopez-Madrid et al. in 2018, which showed that Filipino meal planners' awareness of and adherence to Food-based Dietary Guidelines were low (Lopez-Madrid et al., 2018).

Although food insecurity and lack of dietary diversity are widespread in the Philippines, they are insufficiently examined and assessed for risk factors among mothers and young children, the two important life stages that are crucial to prevent malnutrition. Research findings suggest that household with moderate to severe food insecurity has lower dietary diversity scores compared to food-secure households (Chandrasekhar et al., 2017). The degree to which households experience food insecurity and how it is reflected on the diversity of foods consumed by mothers, children, and mother-child pairs in the Philippine situation merits an investigation. To date, most studies on food insecurity and or dietary diversity in low- and middle-income countries have dealt with understanding its association with nutritional status (Dinku, 
Mekonnen \& Adilu, 2020), but scant on studies looking at the association of food security and dietary diversity scores (DDS) among mothers and children. DDS is correlated with nutrient adequacy (Daniels et al., 2009) and is a proxy measure of the micronutrient adequacy of complementary foods provided to infants and young children, as well as the diet of mothers (FAO \& FHI 360, 2016). Furthermore, counting the dietary diversity is one of the means of measuring food quality vis-à-vis socioeconomic status and malnutrition among children (UNICEF, 2019) and mothers (FAO, 2021).

This study was therefore conducted to fill this research gap to determine the association of HFS and meeting the DDS of mothers, children, and mother-child pairs. Specifically, it aimed to determine the proportion of mothers, children aged 6 to 36 months, and mother-child pairs meeting the DDS by food insecurity levels, and to determine the factors associated with meeting the DDS of these population groups. Looking at both the HFS, which measures food adequacy, and the DDS of mothers and children as a proxy measure of nutrient adequacy of their diet will provide a broader understanding of their nutritional wellbeing. The results of this study will also strengthen the development of evidencebased policies to target the severely and moderately food-insecure households with mothers and young children with less diverse diets in the country.

\section{MATERIALS AND METHODS}

\section{Study design and participants}

This study was a cross-sectional study utilising secondary data from the 2015 Updating Survey. Prior to the conduct of the ENNS in 2018-2020, the Updating Survey was being conducted every 3-5 years nationwide by the DOST-FNRI as a designated statistical activity that aimed to generate nutrition and health statistics of the Filipino citizenry. The 2015 Updating Survey was conducted from July-November 2015 covering all 17 regions and 80 of 81 provinces, excluding Batanes.

The 2015 Updating Survey adopted the 2003 Master Sample (MS) developed by the Philippine Statistics Authority (PSA). It used a three-stage sampling design where the first stage was the selection of Primary Sampling Units (PSUs), consisting of one barangay or a combination of contiguous barangays with at least 500 households each (Figure 1). Enumeration areas consisting of 150-200 households from these PSUs were identified, from which housing units were randomly selected. The last stage was the random selection of the households, which was the ultimate sampling unit (DOST-FNRI, 2016).

From the PSA list of 48,178 households eligible for interviews, a total of 42,310 households participated in the 2015 Updating Survey. From these, households with both mothers and children aged 6-36 months were 7,528 . Upon exclusion of mother-child pairs with missing information, the households with mother-child pairs included in the study were 6,692.

\section{Data collection}

Data were obtained by trained field researchers using face-to-face interviews among mothers with children aged 6-36 months with a questionnaire developed and pre-tested by the DOST-FNRI. The questionnaire was uploaded in the electronic Data Collection System (eDCS) to collect all relevant information on households, mothers, and children. Questionnaires were written in English with translations in Filipino and other major dialects. In survey areas where Filipino was not the spoken language, deliberate hiring of local researchers 


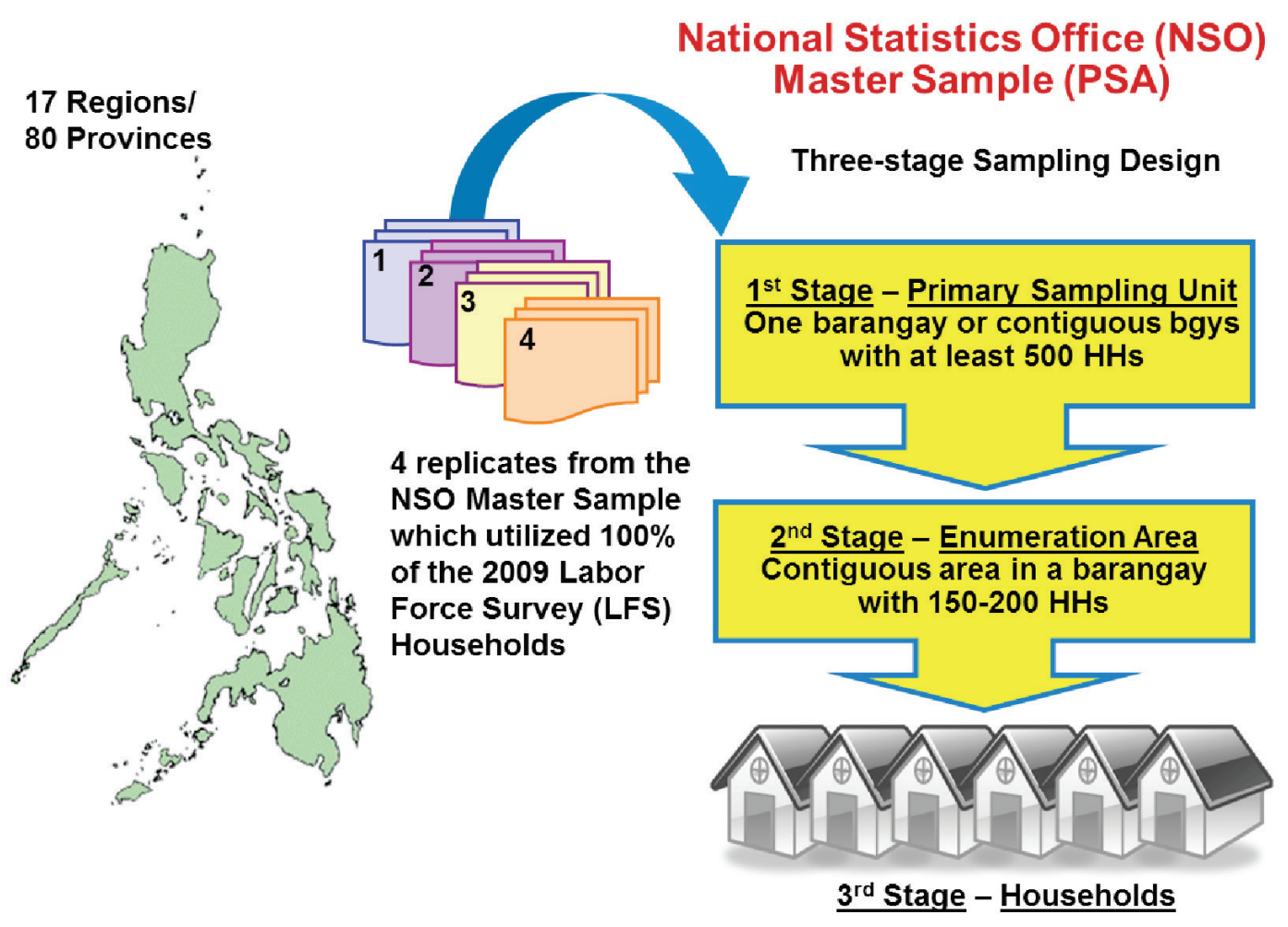

Figure 1. Sampling design of the 2015 Updating of Nutritional Status of Filipino Population

from these areas who can speak the local dialects was done. In addition, the survey team also sought the help of hired local aides in the survey area to act as interpreters during the interview.

Household food security status was determined using the HFIAS assessment tool adapted from the United States Agency for International Development (USAID) Food and Nutrition Technical Assistance (FANTA) Project (Coates, Swindale \& Bilinsky, 2007). The HFIAS is a nine-item questionnaire regarding difficulties experienced in securing food needs for the past month from the date of the interview. The nine questions or experiences were the following: 1) worry about food, 2) unable to eat preferred foods, 3) eat just a few kinds of foods, 4) eat foods they do not want to eat, 5) eat a smaller meal, 6) eat fewer meals in a day, 7) no food of any kind in the household, 8) go to sleep hungry, and 9) go a whole day and night without eating.

The dietary diversity of mothers and their children aged 6-36 months were obtained from the mother's and child's one-day food intake through a 24-hour food recall using a paperbased questionnaire and measuring tools. The mother was asked about her and her child's complete food intake from the time of waking up until at night before going to sleep. Selected socio-demographic, socioeconomic, and reproductive characteristics of mothers, children, and households were also obtained using face-to-face interviews.

\section{Study variables}

The dependent variables or the outcomes of interest of the study included the 
mothers, children, and mother-child pairs meeting the DDS.

1. Mothers meeting the DDS - a mother who consumed food items from at least five out of ten food groups (FAO, 2010) that were identified from their 24-food recall interview.

2. Children meeting the DDS - a child who consumed food items from at least four out of seven food groups that were identified from their 24-food recall interview.

3. Mother and child pair meeting the DDS - the mother who consumed food items from at least five out of ten food groups, while the child who consumed food items from at least four out of seven food groups.

The independent variable was household food security; maternal, child, and household characteristics were included as covariates in the study.

1. Household Food Security - using HFIAS, a household was food secure if it never experienced the occurrence of any of the nine food insecurity questions. Otherwise, the household was food insecure if it experienced any of the nine food insecurity questions. By frequency of occurrence of the nine food insecurity questions, the household was classified as mildly food insecure, moderate food insecure, and severely food insecure.

2. Maternal variables - included age $(<20$ and $\geq 20$ years); educational attainment (primary level or less, secondary level, tertiary and above), employment status (employed, not employed), and the number of children (one child, 2-3 children, 4-5 children, $\geq 6$ children).
3. Child variables - included age in months (6-11 months, 1223 months, 24-36 months); sex (male or female); and current breastfeeding status (breastfed or not breastfed).

4. Household variables - included sex of household head (male or female); household size (2-4 members, 5-6 members, 7-8 members, $\geq 9$ members); place of residence (rural or urban); and wealth quintile ( $1^{\text {st }}$ quintilepoorest, $2^{\text {nd }}$ quintile-poor, $3^{\text {rd }}$ quintile-middle, $\quad 4^{\text {th }}$ quintilerich, $5^{\text {th }}$ quintile-richest). Wealth quintile served as a proxy indicator for wealth status of households derived using data collected from the socio-economic component of the 2015 Updating Survey using Principal Component Analysis (PCA).

\section{Computation of dietary diversity scores of mothers and children}

The DDS was calculated by adding up the number of groups consumed by the mother and the child in the previous 24 hours. For maternal DDS, the food groups were categorised into ten groups classified according to the Food and Agriculture Organization (FAO) groupings such as 1) starchy staples, 2) beans and peas, 3) nuts and seeds, 4) dairy, 5) flesh foods, 6) eggs, 7) vitamin A-rich dark green leafy vegetables, 8) other vitamin A-rich vegetables and fruits, 9) other vegetables, and 10) other fruits. If at least one food item was consumed from a food group, that group was given a score of one. All positive scores were then added together to give the mother a final DDS ranging from 0 to 10 (FAO \& FHI 360, 2016).

For child DDS, the food items were categorised into seven food groups, namely: 1) grains, roots, and tubers, 
2) legumes and nuts, 3) milk and milk products, 4) flesh foods including meat, fish, poultry, and liver/organ meats, 5) eggs, 6) vitamin A-rich fruits and vegetables, and 7) other fruits and vegetables, using a scoring system adopted from the World Health Organization (WHO). Breast milk was not included in the DDS computation. Similarly, if at least one food item was consumed by the child from a food group, that group was given a score of one. All positive scores were then added together for the child's final DDS.

A mother who consumed food items from at least five out of ten food groups (FAO, 2010) and a child who consumed food items from at least four out of seven food groups were considered to have a high quality diet, thus meeting dietary diversity (WHO, UNICEF, IFPRI, UC, FANTA AED \& USAID, 2008). A mother-child pair meeting the DDS was considered when both mother and child met their respective DDS.

\section{Computation of household food security}

The household's food security score from HFIAS varied from zero (food secure) to 27 (maximum food insecurity) based on the frequency of occurrence of the nine questions being asked. For each question, a score of zero was given if the situation never occurred, one if the situation occurred rarely (one to two times per month), two if the situation occurred sometimes (three to ten times a month), and three if the situation occurred frequently (>10 times a month) (Coates et al., 2007). Based on the responses, the study computed the level of household food security as food secure, mildly food insecure, moderate food insecure, and severely food insecure, as well as by dichotomous classification of food secure and food insecure by combining mildly food insecure, moderate food insecure, and severely food insecure as food insecure.

\section{Data processing and analysis}

Descriptive statistical analysis included estimation of frequencies, weighted means, and proportions. Bivariate analysis was conducted and chi-square test was used to test the significance of the association between the dependent and independent variables. All variables with significant associations with meeting DDS of mothers, children, and mother-child pairs were entered into the multivariate logistic regression analysis. The level of significance was set at $p<0.05$ for all tests performed. Analyses were done using Stata version 15 (StataCorp LLC, Texas, USA).

\section{Ethical considerations}

The 2015 Updating Survey was approved by the Food and Nutrition Research Institute's Institutional Ethics Review Committee (FIERC) under the protocol code FIERC-2015-006. Oral and written consent was obtained from the respondents before actual data collection, which included information on the different components of the 2015 Updating Survey, detailed data collection procedures, and non-disclosure of information for anonymity and confidentiality purposes. The content of the consent form has been published elsewhere (DOST-FNRI, 2016).

\section{RESULTS}

\section{Sample characteristics}

Socio-demographic characteristics of the study population are shown in Table 1. By maternal characteristics, almost all mothers (95.1\%) were 20 years old and above. The majority of them had secondary level education (51.0\%) and were not employed (76\%). Nearly half of the mothers had 2-3 children 
Table 1. Socio-demographic and socio-economic characteristics of households, mothers, and children: Philippines, 2015 (n=6,692)

\begin{tabular}{|c|c|c|c|}
\hline Characteristics & $n$ & $\begin{array}{c}\text { Proportion } \\
\text { (\%) }\end{array}$ & $S E$ \\
\hline \multicolumn{4}{|l|}{ Maternal characteristics } \\
\hline \multicolumn{4}{|l|}{ Age } \\
\hline$<20$ years old & 319 & 4.9 & 0.3 \\
\hline$\geq 20$ years old & 6,373 & 95.1 & 0.3 \\
\hline \multicolumn{4}{|l|}{ Education background } \\
\hline Primary level or less & 1470 & 20.3 & 0.6 \\
\hline Secondary level & 3,360 & 51.0 & 0.8 \\
\hline Tertiary and above & 1,862 & 28.8 & 0.7 \\
\hline \multicolumn{4}{|l|}{ Employment status } \\
\hline Employed & 1,521 & 23.7 & 0.6 \\
\hline Not employed & 5,171 & 76.3 & 0.6 \\
\hline \multicolumn{4}{|l|}{ Parity } \\
\hline 1 child & 1,583 & 24.4 & 0.6 \\
\hline 2-3 children & 2,888 & 43.8 & 0.7 \\
\hline 4-5 children & 1,338 & 19.5 & 0.5 \\
\hline$\geq 6$ children & 883 & 12.3 & 0.5 \\
\hline \multicolumn{4}{|l|}{ Child characteristics } \\
\hline \multicolumn{4}{|l|}{ Age } \\
\hline 6-11 months old & 1,454 & 21.8 & 0.5 \\
\hline $12-23$ months old & 2,595 & 39.1 & 0.6 \\
\hline $24-36$ months old & 2,643 & 39.2 & 0.6 \\
\hline \multicolumn{4}{|l|}{ Sex } \\
\hline Male & 3,369 & 49.9 & 0.7 \\
\hline Female & 3,323 & 50.1 & 0.7 \\
\hline \multicolumn{4}{|l|}{ Breastfeeding status } \\
\hline Breastfed & 3,956 & 59.8 & 0.7 \\
\hline Not breastfed & 2,736 & 40.2 & 0.7 \\
\hline \multicolumn{4}{|l|}{ Household characteristics } \\
\hline \multicolumn{4}{|l|}{ Sex of household head } \\
\hline Male & 5,798 & 86.0 & 0.5 \\
\hline Female & 894 & 14.0 & 0.5 \\
\hline \multicolumn{4}{|l|}{ Household size } \\
\hline 2-4 members & 1,223 & 18.6 & 0.6 \\
\hline 5-6 members & 2,326 & 34.2 & 0.7 \\
\hline $7-8$ members & 1,763 & 26.2 & 0.6 \\
\hline$\geq 9$ members & 1,380 & 21.1 & 0.7 \\
\hline \multicolumn{4}{|l|}{ Type of residence } \\
\hline Rural & 4,015 & 52.5 & 1.0 \\
\hline Urban & 2,677 & 47.5 & 1.0 \\
\hline \multicolumn{4}{|l|}{ Wealth quintile } \\
\hline Poorest & 1,940 & 25.0 & 0.7 \\
\hline Poor & 1,575 & 21.7 & 0.6 \\
\hline Middle & 1,272 & 20.2 & 0.6 \\
\hline Rich & 1,060 & 18.1 & 0.6 \\
\hline Richest & 845 & 15.0 & 0.6 \\
\hline \multicolumn{4}{|l|}{ Food security status } \\
\hline Food secure & 1,418 & 21.9 & 0.7 \\
\hline Food insecure & 5,274 & 78.1 & 0.7 \\
\hline \multicolumn{4}{|l|}{ Food security levels } \\
\hline Mild food insecure & 840 & 12.9 & 0.5 \\
\hline Moderate food insecure & 2,632 & 38.2 & 0.8 \\
\hline Severe food insecure & 1,802 & 27.0 & 0.7 \\
\hline
\end{tabular}


Table 1. Socio-demographic and socio-economic characteristics of households, mothers, and children: Philippines, $2015(n=6,692)$ [Cont'd]

\begin{tabular}{lccc}
\hline \multicolumn{1}{c}{ Characteristics } & $n$ & $\begin{array}{c}\text { Proportion } \\
(\%)\end{array}$ & $S E$ \\
\hline Dietary diversity score: Mothers & & & \\
$\quad$ Not meeting DDS & 4,693 & 69.5 & 0.7 \\
$\quad$ Meeting DDS & 1,999 & 30.5 & 0.7 \\
Dietary diversity score: Children & & & \\
$\quad$ Not meeting DDS & 4,200 & 62.4 & 0.7 \\
$\quad$ Meeting DDS & 2,492 & 37.6 & 0.7 \\
Dietary diversity score: Mother-Child & & & 0.5 \\
$\quad$ Not meeting DDS & 5,636 & 84.2 & 0.5 \\
$\quad$ Meeting DDS & 1,056 & 15.8 & \\
\hline
\end{tabular}

(44\%). An almost equal proportion of children belonged to the age groups of 12-23 months and 24-36 months at $39.1 \%$ and $39.2 \%$, respectively. By sex, males and females had almost equal representations. Most of the children were breastfed (59.8\%). By household characteristics, the majority of motherchild pairs' households were headed by a male and with 5-6 household members. More than half were living in rural $(52.5 \%)$ areas, while higher proportions were from the poorest $(25.0 \%)$ and foodinsecure households (78.1\%). Among the food insecure households, the majority were experiencing moderate food insecurity at $38.2 \%$, while $27.0 \%$ were experiencing severe food insecurity. About one-third of the mothers (30.5\%) and a little over one-third of the children $(37.6 \%)$ met the DDS. However, when combined as mother-child pairs, only $15.8 \%$ met the DDS.

\section{Meeting dietary diversity score of mothers, children, and mother-child pairs by household food security status}

Table 2 shows the percentage distribution of meeting and not meeting the DDS among mothers, children, and mother-child pairs by household food

Table 2. Percentage distribution of meeting and not meeting the DDS among mothers, children, and mothers and children by household food security status $(n=6,692)$

\begin{tabular}{|c|c|c|c|c|c|c|}
\hline \multirow[b]{2}{*}{$\begin{array}{c}\text { Household food security } \\
\text { status }\end{array}$} & \multicolumn{2}{|c|}{ Mother* } & \multicolumn{2}{|c|}{ Child* } & \multicolumn{2}{|c|}{ Mother and child* } \\
\hline & $\begin{array}{c}\text { Not } \\
\text { meeting } \\
D D S\end{array}$ & $\begin{array}{l}\text { Meeting } \\
\text { DDS }\end{array}$ & $\begin{array}{c}\text { Not } \\
\text { meeting } \\
D D S\end{array}$ & $\begin{array}{l}\text { Meeting } \\
\text { DDS }\end{array}$ & $\begin{array}{c}\text { Not } \\
\text { meeting } \\
D D S\end{array}$ & $\begin{array}{l}\text { Meeting } \\
\text { DDS }\end{array}$ \\
\hline Food secure & 60.7 & 39.3 & 58.1 & 41.9 & 79.3 & 20.7 \\
\hline Food insecure & 72.0 & 28.0 & 63.6 & 36.4 & 85.6 & 14.4 \\
\hline \multicolumn{7}{|l|}{ Food insecurity level } \\
\hline Mild food insecure & 60.7 & 35.0 & 58.1 & 42.6 & 79.3 & 19.7 \\
\hline Moderate food insecure & 65.0 & 29.4 & 57.4 & 37.7 & 80.4 & 15.1 \\
\hline Severe food insecure & 70.6 & 22.6 & 62.4 & 31.8 & 84.9 & 10.9 \\
\hline
\end{tabular}




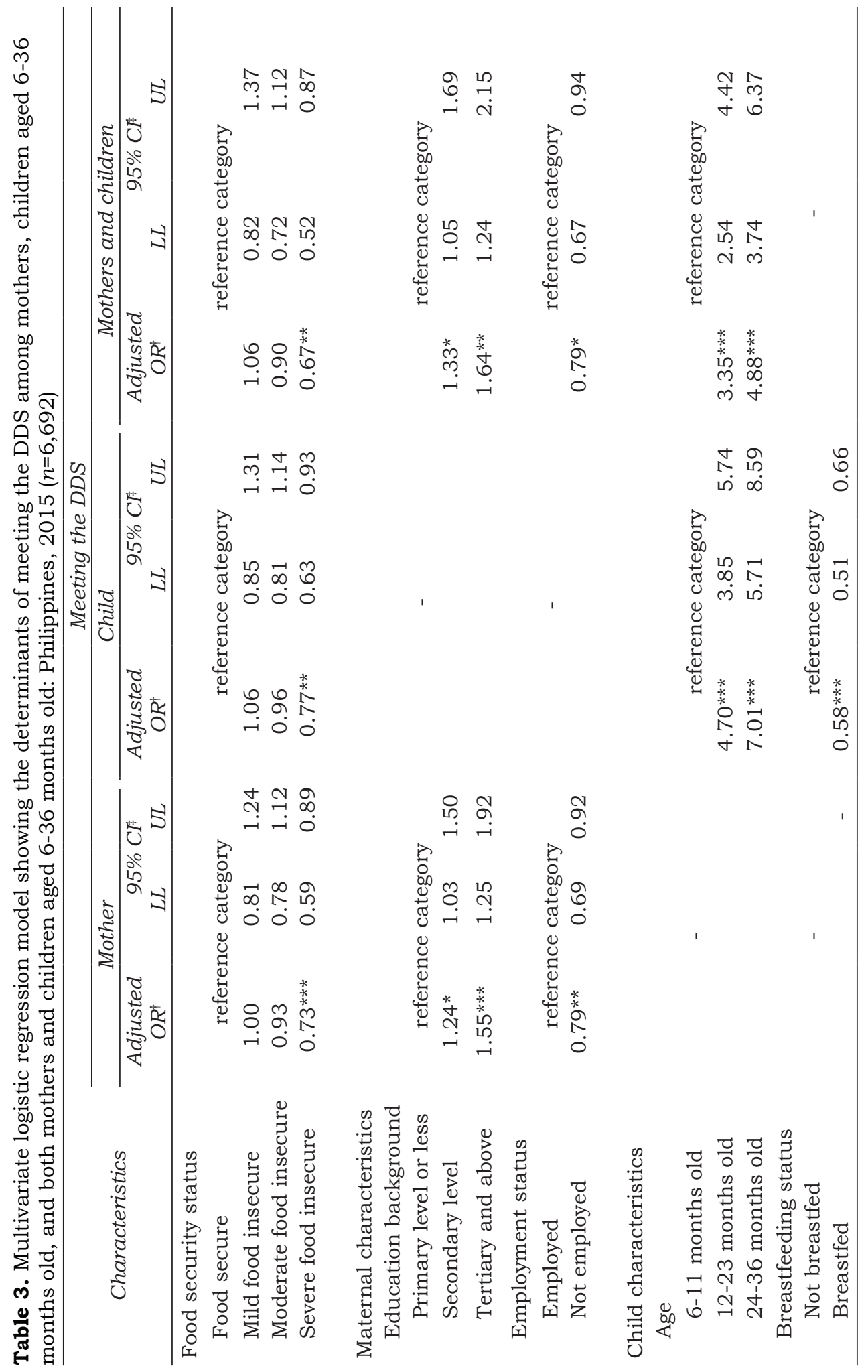




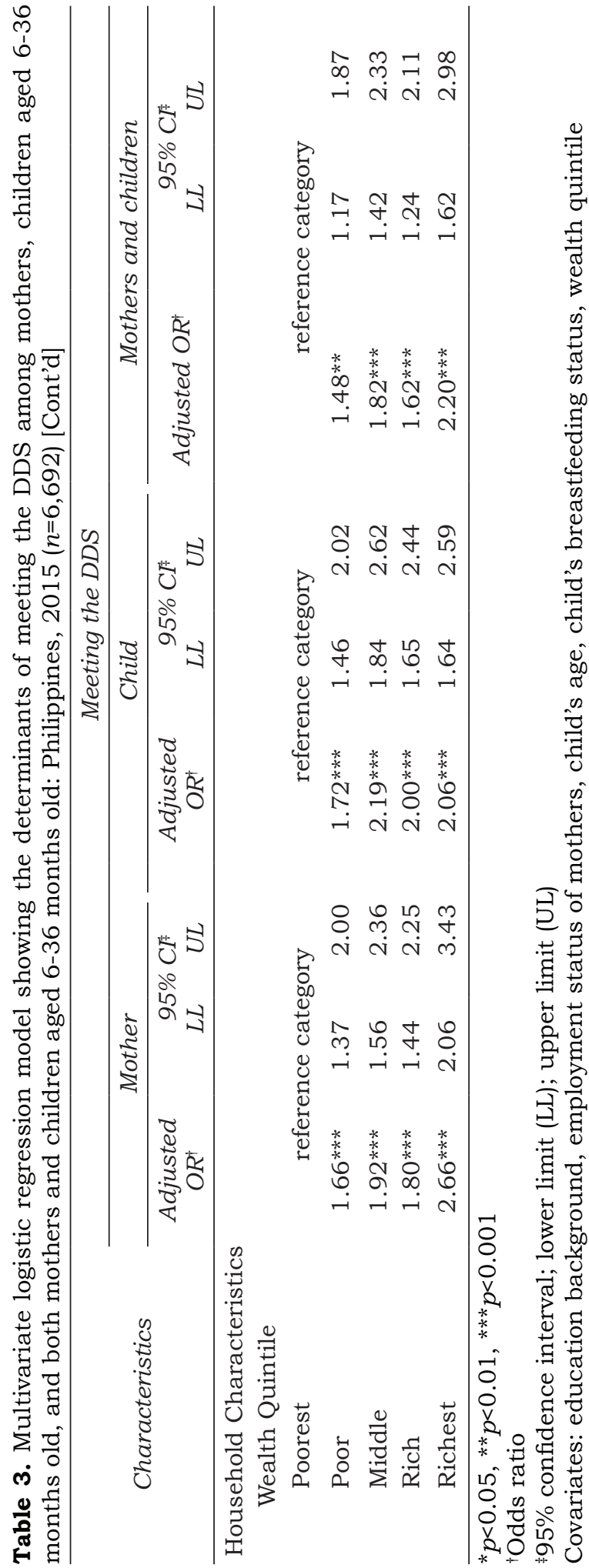

security status. Among mothers, the proportion of meeting the DDS was higher among food secure $(39.3 \%)$ than food insecure (28.0\%) households. Similarly, among children, the proportion meeting the DDS was higher among food secure $(41.9 \%)$ than food insecure $(36.4 \%)$ households. Among mother-child pairs, only $14.4 \%$ met the DDS in foodinsecure households, while $20.7 \%$ met the DDS in food-secure households. The proportion of meeting the DDS decreased as the levels of household food insecurity increased.

\section{Factors associated with meeting dietary diversity score of mothers, children, and mother-child pairs}

After controlling for the effects of other variables, the final model of factors significantly associated with meeting the DDS of mothers, children, and mother-child pairs are presented in Table 3. For mothers, the factors were household food security, education background, employment status, and wealth quintile; while for children, the factors were household food security, age, breastfeeding status, and wealth quintile. Among mother-child pairs, factors significantly associated with meeting DDS were household food security, education background, employment status of mothers, age of the child, breastfeeding status, and wealth quintile.

Results showed that mothers who experienced severe food insecurity were $27 \%$ less likely to meet DDS than mothers in foodsecure households. Mothers with secondary level education and had 
at least tertiary education were $24 \%$ and $55 \%$ more likely, respectively, to meet the DDS than those with primary level or less. Unemployed mothers were $21 \%$ less likely to meet the DDS than their employed counterparts. Wealth quintile was also found to be significantly associated with DDS, wherein those in the richest quintile were 2.66 times more likely to meet DDS than those in the poorest quintile. The likelihood of meeting DDS increased as wealth status improved.

Children with severe food-insecure households were $23 \%$ less likely to meet the DDS than mothers in foodsecure households. Children aged 1223 months old were 4.70 times more likely to meet the DDS compared to the reference group. Moreover, those in the 24-36 months old age group were 7.01 times more likely to meet the DDS compared to the reference group. Similar to mothers, the likelihood of meeting DDS among children generally increased with the improvement of wealth status.

Among mother-child pairs, there was a decreased likelihood of meeting the DDS as the household experienced severe food insecurity. The likelihood of meeting the DDS was $64 \%$ more likely among mothers with at least tertiary education compared to those with no grades completed. The likelihood of meeting the DDS increased as education level increased. Unemployment decreased the likelihood of meeting the DDS by $21 \%$. In terms of child characteristics, those in the 12-23 months old age group were 3.35 times more likely to meet the DDS, and those in the 24-36 months old age group were 4.88 times more likely to meet the DDS than their younger counterparts. The likelihood of meeting DDS increased as wealth status improved among motherchild pairs.

\section{DISCUSSION}

\section{Household food security status in association with meeting the minimum DDS of mothers and children aged 6-36 months}

The study revealed the widespread problem of HFS in the country. Findings of the study showed that meeting the DDS for both mothers and children aged 6-36 months and when combined as mother-child pairs was significantly associated with their level of household food security status. Mothers and children belonging to food-secure households were more likely to meet their minimum DDS than those belonging to food-insecure households. Furthermore, the likelihood of not meeting the DDS increased with the increasing severity of household food insecurity. The results are consistent with a study in Northern Albania, in which it was found that the more severe the food insecurity in the household, the less varied the women's diets were (MDGF \& UN Albania, 2012). Another study done in Bangladesh, Vietnam, and Ethiopia reported that food security was positively associated with maternal dietary diversity (Nguyen et al., 2013). Women, especially mothers, are the gatekeepers of their family's diet and are entrusted with the major responsibility of selecting, preparing, and serving nutritious foods to support families and households. However, the diets of women and mothers are often overlooked, along with the potential impacts of poor diets on women and their families. Furthermore, mothers are likely to reduce their intakes to secure those of infants and small children.

A significant association of meeting the minimum DDS and household food security among children was also found in other studies. It was reported in studies in Nicaragua and Northern Ghana that improved household food 
security was associated with meeting children's dietary diversity (Agbadi, Urke \& Mittelmark 2017). Another study in Nepal reported the same finding which stated that more children from food-secure households received the recommended dietary diversity compared to children from food-insecure households (Hellen Keller International, 2010).

\section{Factors on meeting the DDS among mothers}

Meeting the minimum DDS of five food groups among mothers was found to be significantly associated with their household food security, educational attainment, employment status, and household wealth status. Those with at least a tertiary level education and in the richest quintile were more likely to meet the DDS, while those who were unemployed were less likely to meet DDS. Mothers in food-secure households were significantly more likely to meet DDS than those in food-insecure households.

Of the three most commonly used indicators i.e., educational level, income, and occupation, educational level is the strongest and most consistent in predicting health behaviours (Winkleby et al., 1992). Parents with lower educational attainment experience difficulties, such as lack of knowledge, skills, time, money, and other resources, to create healthy home environments and model healthy behaviours for their children. In the context of this study, women with higher education might have acquired essential information on appropriate feeding practices (Kiboi, Kimiywe \& Chege, 2017). On the other hand, mothers who were not employed had lower odds of meeting the minimum DDS than employed mothers. The same result was reported in the same study, wherein more employed women attained minimum dietary diversity as compared to the non-employed. This can be explained by the fact that women who are employed have a regular income, which increases their chances of access to food.

By wealth status, mothers in the higher wealth quintiles were more likely to meet the minimum DDS compared to those in the lower wealth quintiles. In a study by Hatloy et al. (2000), it has been demonstrated that as income rises, households tend to diversify their diets, which in turn increases their micronutrient intakes and improves their nutrient adequacy. Also, people living in poverty or extreme poverty have limited purchasing power, which directly affects their ability to buy a variety of foods.

\section{Factors on meeting the minimum DDS among children aged 6-36 months}

Meeting the DDS of at least four food groups among children aged 6-36 months was associated with their household food security, age, breastfeeding status, and household wealth status. A higher proportion of older children (12-23 months and 24-36 months) had significantly higher odds of meeting their minimum DDS as compared to younger children aged 6-11 months. Similar studies have also found an association between the age of a child and minimum dietary diversity (Amugsi, Mittelmark \& Oduro, 2015; Nguyen et al., 2013). This is expected because children gradually consume a greater variety and quantity of foods from six months onwards and in developing countries, they are likely to transition to family foods during their second year (Nguyen et al., 2013). Younger children $<9$ months old had lower odds of meeting the DDS and this could be due to the late introduction of complementary foods to infants or if the mother had introduced complementary 
feeding on time, they only included milk or cereal products like gruel. Another reason could be due to the mother's perception that the younger the child, the poorer the ability of the child's intestine to digest solid foods (Beyene, Worku \& Wassie, 2015).

Breastfed children were less likely to meet their minimum DDS than nonbreastfed children. One possible reason would be that the breastfed children were not introduced to complementary foods in a timely manner and their mothers were not aware of or were not knowledgeable on the importance of adequate dietary diversity in meeting their children's nutritional needs.

Children in the richer wealth quintiles had greater chances of meeting their minimum DDS than those in the poorer wealth quintiles. This is consistent with the finding in another study, which stated that the child's dietary diversity was positively associated with wealth index (Amugsi et al., 2015). Higher economic status is associated with improved access to material resources including foods. Direct access to food may allow households to provide their children greater amounts of food and a more diversified diet that is richer in micronutrients.

In light of this finding, it is critically important that interventions that are to be designed and implemented should address the food insecurity issues of economically disadvantaged households and their dietary modification towards a healthier and more diverse diet. Social and behavioural change interventions that target maternal and child dietary diversity are also recommended to emphasise the importance of feeding the child nutritious family foods and as timely as suggested. In addition, the promotion of women empowerment is also encouraged to improve not only the infant and young child feeding practices, but also the dietary diversity of every household member.

\section{Strengths and limitations}

One of the strengths of the study was the large, nationally representative sample size of the data set. The rich dataset has information on the DDS of both mothers and their children, as well as household food security that allowed the authors to determine in one study the association of household food security with DDS of mothers and children, and identify the risk factors for meeting the DDS among these population groups. The findings, however, can be affected by recall bias since the survey tools used - the 24hour food recall and the HFIAS were dependent on the memory of the mothers to recall past events. The study design, being cross-sectional, also limited the causal relationships of the risk factors identified.

\section{CONCLUSION}

The findings showed that HFS was significantly associated with meeting the DDS of mothers, children aged 6-36 months, and mother-child pairs. The severity of household food insecurity further decreased the mothers' and children's likelihood of meeting the DDS. Among mothers, meeting the DDS of at least five food groups was significantly associated with their level of food security, education background, employment status, and wealth status. Among children, meeting the DDS of at least four food groups was significantly associated with their level of food security, age, breastfeeding status, and wealth status. For mother-child pairs, the factors significantly associated with meeting the DDS were household food security status, education background, employment, child's age, and wealth status. The results of this study 
provided evidence on how the level of household food security was associated with meeting the DDS of mothers, children, and mother-child pairs, and the need to support the $1^{\text {st }} 1000$ days of life. Results can be used as a basis to formulate appropriate policies to address the widespread food insecurity among Filipinos, which impacts the most vulnerable population groups of mothers and children.

\section{Acknowledgments}

The contributions of Ms. Catherine J. Silvestre and Ms. Merjurie S. Miparanum, the project staffs, are greatly recognised. The authors also acknowledge the participants, field researchers, and all the health and nutrition community workers involved in the 2015 Updating Survey.

\section{Authors' contributions}

MOG, principal investigator, conceptualised and designed the study, prepared the draft of the manuscript and reviewed the manuscript; MLVM, conducted the data analysis and interpretation of the study, assisted in drafting the manuscript, and reviewed the manuscript; CGM, assisted on the data interpretation and reviewed the manuscript.

\section{Conflict of interest}

The authors declare that they have no competing interests.

\section{References}

Agbadi P, Urke HB \& Mittelmark MB (2017). Household food security and adequacy of child diet in the food insecure region north in Ghana. PLOS ONE 12(5):e0177377.

Amugsi DA, Mittelmark MB \& Oduro A (2015). Association between maternal and child dietary diversity: An analysis of the Ghana Demographic and Health Survey. PLOS ONE 10(8):e0136748

Beyene M, Worku AG \& Wassie MM (2015). Dietary diversity, meal frequency and associated factors among infant and young children in Northwest Ethiopia: a cross-sectional study. BMC Public Health 15:1007.

Brizuela V \& Tunçalp Ö (2017). Global initiatives in maternal and newborn health. Obstet Med 10(1):21-25. https://doi. org/10.1177/1753495X16684987.
Chandrasekhar S, Aguayo VM, Krishna V \& Nair R (2017). Household food insecurity and children ss dietary diversity and nutrition in India. Evidence from the comprehensive nutrition survey in Maharashtra. Matern Child Nutr 13(S2):e12447. doi:10.1111/ mcn. 12447.

Coates J, Swindale A \& Bilinsky P (2007). Household Food Insecurity Access Scale (HFIAS) for Measurement of Household Food Access: Indicator Guide (v. 3). Food and Nutrition Technical Assistance Project, Academy for Educational Development, Washington, D.C.

Daniels MC, Adair LS, Popkin BM \& Truong YK (2009). Dietary diversity scores can be improved through the use of portion requirements: An analysis in young Filipino children. Eur J Clin Nutr 63(2):199-208. https://doi.org/10.1038/ sj.ejcn. 1602927

Dinku AM, Mekonnen TC \& Adilu GS (2020). Child dietary diversity and food (in)security as a potential correlate of child anthropometric indices in the context of urban food system in the cases of north-central Ethiopia. $J$ Health, Popul Nutr 39(1):1-11. https://doi. org/10.1186/s41043-020-00219-6.

DOST-FNRI (2016). Philippine Nutrition Facts and Figures 2015: Updating of Nutritional Status of Filipino Children and Other Population Groups Overview. Department of Science and Technology - Food and Nutrition Research Institute, Metro Manila, Philippines.

DOST-FNRI (2021). 2018 and 2019 Expanded National Nutrition Survey Results. Department of Science and Technology - Food and Nutrition Research Institute, Taguig City. http:// enutrition.fnri.dost.gov.ph/site/presentation. php?year=2019 [Retrieved August 29 2021].

FAO (2010). Guidelines for measuring household and individual dietary diversity. Food and Agriculture Organization, Rome.

FAO (2021). Minimum dietary diversity for women. Food and Agriculture Organization, Rome. https://doi.org/10.4060/cb3434en

FAO \& FHI 360 (2016). Minimum Dietary Diversity for Women: A Guide for Measurement. Food and Agriculture Organization, Rome.

FAO, IFAD, UNICEF, WFP \& WHO (2019). The State of Food Security and Nutrition in the World 2019. Safeguarding against economic slowdowns and downturns. Food and Agriculture Organization, Rome. 
Hatloy A, Hallund J, Diarra MM \& Oshaug A (2000). Food variety, socioeconomic status and nutritional status in urban and rural areas in Koutiala (Mali). Public Health Nutr 3(1):57-65.

Hellen Keller International (2010). Household food insecurity and nutritional status of children aged 6-23 months in Kailali District of Nepal. Nepal Nutrition and Food Security Bulletin. Nepal.

iPrice Group (2021). Online Groceries in the Philippines Are Soaring \& Market Items Are the Cheapest in SEA. https://iprice.ph/ trends/insights/online-grocery-sites-in-thephilippines-are-soaring/ [Retrieved September 20 2021].

Keats EC, Das JK, Salam RA, Lassi ZS, Imdad A, Black RE \& Bhutta ZA (2021). Effective interventions to address maternal and child malnutrition: an update of the evidence. Lancet Child Adolesc Health 5(5): 367-384. https:// doi.org/ 10.1016/S2352-4642(20)30274-1

Kiboi W, Kimiywe J \& Chege P (2017). Determinants of dietary diversity among pregnant women in Laikipia County, Kenya: a cross-sectional study. BMC Nutr 3:12.

Lopez-Madrid MM, Acuin CCS, Orense CL, Duante CA, Tan RCA \& Capanzana MV (2018). Awareness of and adherence to the food based dietary guidelines among household meal planners in the Philippines. Philipp $J$ Sci 147(3):523-535.

Mbuya NV, Demombynes G, Piza SF \& Adona AJ (2021). Undernutrition in the Philippines: scale, scope, and opportunities for nutrition policy and programming. International Development in Focus. World Bank, Washington, DC. doi:10.1596/978-1-4648-1701-4. License: Creative Commons Attribution CC BY 3.0 IGO

MDGF \& UN Albania (2012). Baseline nutrition and food security survey: summary and key findings. Millennium Development Goals Achievement Fund and United Nations Albania, Tirana.
Nguyen PH, Avula R, Ruel MT, Saha KK, Ali D, Tran LM...Rawat R (2013). Maternal and child dietary diversity are associated in Bangladesh, Vietnam and Ethiopia. J Nutr 143:1176-1183.

Pérez-Escamilla R (2017). Food security and the 2015-2030 sustainable development goals: From human to planetary health. Curr Dev Nutr 1(7):1-8. https://doi.org/10.3945/ cdn. 117.000513

PSA (2019). Proportion of Poor Filipinos was Estimated at 16.6 Percent in 2018. Poverty Statistics Press Release. Philippine Statistics Authority, Quezon City, Philippines. https:/ / psa.gov.ph/poverty-press-releases / nid/144752 [Retrieved August 14 2021].

SWS (2020). Fourth Quarter 2019 Social Weather Survey: Self-Rated Poverty rises by 12 points to 5-year-high 54\%. Social Weather Stations Quezon City, Philippines. http://www.sws.org. $\mathrm{ph} /$ swsmain / artcldisppage / ?artcsyscode $=\mathrm{AR}$ T - 20200123140450 [Retrieved September 20 2021].

UNICEF (2019). The State of the World's Children 2019. Children, Food and Nutrition: Growing well in a changing world. United Nations Children's Fund, New York.

Winkleby MA, Jatulis DE, Frank E \& Fortmann SP (1992). Socioeconomic status and health: How education, income, and occupation contribute to risk factors for cardiovascular disease. Am $J$ Public Health 82(6):816-820. https://doi. org/10.2105/AJPH.82.6.816

WHO, UNICEF, IFPRI, UC, FANTA AED \& USAID (2008). Indicators for assessing infant and young child feeding practices. Part 1: Definitions. World Health Organization, Geneva. 